\title{
Energy balance in patients with advanced NSCLC, metastatic melanoma and metastatic breast cancer receiving chemotherapy -
} a longitudinal study

\author{
MN Harvie*,I, A Howell', N Thatcher', A Baildam ${ }^{2}$ and I Campbell ${ }^{3}$ \\ 'Cancer Research UK Department of Medical Oncology, Christie Hospital, Wilmslow Road, Manchester M20 4BX, UK; ${ }^{2}$ University Department of \\ Surgery, South Manchester University Hospitals NHS Trust, Manchester M20 2LR, UK; ${ }^{3}$ University Department of Anaesthesia, South Manchester \\ University Hospitals NHS Trust, Manchester M20 2LR, UK
}

\begin{abstract}
Chemotherapy exerts a variable effect on nutritional status. It is not known whether loss of body fat or fat-free mass (FFM) during chemotherapy relates to diminished dietary intake, failure to meet elevated energy requirements, or to the presence of an acutephase response. We sought to determine prospective measurements of body mass and composition, resting energy expenditure, energy and protein intake, and C-reactive protein over a course of chemotherapy in 82 patients with advanced cancer. There was a large dropout from the study. Prospective measurements were obtained in 19 patients with non-small-cell lung cancer (NSCLC), 12 with metastatic melanoma and 10 with metastatic breast cancer. There were significant increases in energy intake among patients with metastatic breast cancer, $873(266-1480) \mathrm{kJ}$ (mean 95\% Cl; $P<0.0 \mathrm{I})$, and metastatic melanoma, 25I3 (523-4503) kJ $(P<0.0 \mathrm{I})$. Breast cancer patients gained percentage body fat over the course of treatment, $2.1(0.8-3.5 \%)$. Gain or loss of body fat correlated to mean energy intake throughout chemotherapy in patients with NSCLC (Rs $=0.75 \mathrm{I} ; \mathrm{P}<0.0 \mathrm{I}$ ) and metastatic breast cancer (Rs $=0.617 ; P<0.05$ ). The ability to meet or exceed energy requirements led to gains in body fat among patients with metastatic breast cancer and NSCLC, but did not prevent loss of FFM in these groups.

British Journal of Cancer (2005) 92, 673-680. doi:I0.1038/sj.bjc.6602357 www.bjcancer.com
\end{abstract}

(c) 2005 Cancer Research UK

Keywords: metastatic; body composition; energy balance; acute-phase protein response; chemotherapy; longitudinal

Treatment with chemotherapy is linked to loss of weight (i.e. loss of body fat and/or fat-free mass (FFM)) in some, but by no means all, cancer patients (Jardine et al, 1984; Jebb et al, 1994; Sarna et al, 1994). Whether loss of body fat and FFM are related to diminished dietary intake or a failure to meet the elevated energy requirements due to increases in resting energy expenditure associated with cancer and its treatment is not resolved, as there are few prospective data of energy balance among patients receiving chemotherapy. A further consideration is the role of the acutephase response. This has been linked to weight loss through the associated elevations in REE (Staal-van den Brekel et al, 1995) and declines in dietary intake (Wigmore et al, 1997), but may also specifically lead to the depletion of FFM (Simons et al, 1999). The aim of this study was to examine whether changes in dietary intake, resting energy expenditure or the acute-phase response could explain changes in weight and body composition over the course of chemotherapy. We therefore measured body mass, body composition, energy expenditure, energy intake and C-reactive protein (CRP) over several cycles of chemotherapy among patients considered to be at high (non-small-cell lung cancer (NSCLC)) (Buccheri and Ferrigno, 2001) and metastatic melanoma (Smit et al,

*Correspondence: Dr M Harvie; E-mail: m_ harvie@fs I.with.man.ac.uk Received 17 September 2004; revised 7 December 2004; accepted 8 December 2004
1983), and low (metastatic breast) risk of wasting (Jardine et al, 1984).

\section{PATIENTS AND METHODS}

\section{Patients}

A total of 105 patients with advanced NSCLC (stage 111 or IV), 40 with metastatic melanoma and 30 with metastatic breast cancer and scheduled to have chemotherapy were invited to enter the study. None of the patients had received any cancer therapy, that is, surgery, chemotherapy, radiotherapy or endocrine therapy within the previous 3 months. Patients with a prognosis of less than 2 months or severe endocrine abnormalities (e.g. diabetes mellitus, or hyper/hypothyroidism) were excluded. None of the patients received active nutritional intervention. Tumour response to chemotherapy was evaluated according to the standard criteria for melanoma, NSCLC (World Health Organisation, 1979) and breast cancer patients (UICC, 1987).

\section{Measurements}

Patients were seen before commencing chemotherapy, prior to the second chemotherapy cycle, and 1-month post completion of chemotherapy (4-6 cycles). On each occasion, the following measurements were determined: 
Body and FFM: were determined from weight and skinfolds (biceps, triceps subscapular, suprailiac sites) using the equations of Durnin and Womersley (1974). Skinfolds were measured three times by a trained individual and the mean values calculated. The coefficients of variation (CVs) for the determination of fat and FFM from skinfolds by $\mathrm{MH}$ on different occasions were 1.1 and $0.8 \%$.

Mid-arm muscle circumference (MAMC): was calculated from tricep skinfold (TSF) and mid-arm circumference using standard equations (Gurney and Jelliffe, 1973). The CV for the determination of MAMC measured by $\mathrm{MH}$ on different occasions was $1.5 \%$.

Total body potassium: Total body ${ }^{40} \mathrm{~K}$ (TBK), a measure of lean body mass, was measured using a NE8108 shadow shield wholebody monitor (Nuclear Enterprises Ltd, Edinburgh, UK) over $40 \mathrm{~min}$. Relative changes only in ${ }^{40} \mathrm{~K}$ were determined. No attempt was made to perform absolute measurements, as this would have involved administration of radioactive isotopes. Sensitivity of the detectors and instrumental stability were determined after each measurement by performing a static count of potassium standard. The measured values were corrected for changes in sensitivity of the scanner and any change in body size of the patient between measurements using a correction factor previously described (Boddy et al, 1971). Coefficient of variation of measurement was $2 \%$.

Energy and protein intakes: were determined from four-day weighed food diaries completed before each assessment in the week prior to the next chemotherapy cycle to avoid the acute effects of the treatment on dietary intake. Energy intake was determined using the Compeat 4 Nutritional Analysis System (Carlson Bengston Consultants, London) based on the 5th Edition of McCance and Widdowson The Composition of Foods (Holland, 1991).

Resting energy expenditure: was determined by indirect calorimetry (Deltatrac Metabolic Monitor MBM 100, Datex Instrumentation Corporation, Helsinki, Finland) under standardised conditions (Harvie et al, 2004). Oral temperature was recorded using the $3 \mathrm{M}$ Tempa-DOT Thermometer (3M Health Care, USA) calibrated against a National Physics Laboratory thermometer to confirm that patients were apyrexial, and had no overt signs of infection. Resting energy expenditure was also determined in healthy men and women recruited from hospital staff who were one-to-one sex and age matched to the three different cancer subgroups to control for this measurement.

Serum CRP: concentration was measured using a turbidometric method with specific antibodies (Dako Patts, Denmark), measuring the change in absorbance at 340 in an automated analyser (Cobas Mira, Roche). Concentrations were determined using a multi-point calibration curve (Hellsing, 1973) at a CRP concentration of $35 \mathrm{mg} \mathrm{l}^{-1}$. Coefficient of variation was $8.6 \%$.

Performance status: of each patient was evaluated prior to chemotherapy by assigning a Karnofsky score based on the ability to carry out normal activities (Karnofsky and Burchenel, 1949).

Health-related quality of life: was assessed over the week prior to each visit using the self-report general Functional Assessment of Cancer Therapy Scale (FACT-G) (Cella et al, 1993). This 28-item questionnaire assessed physical, functional, emotional and social well-being. Higher scores are associated with better function, with a maximum total score of 116 .

\section{Ethics}

The study was approved by the South Manchester University Hospitals NHS Trust Ethics Committee. All participants provided written informed consent.

\section{Statistical analysis}

These were performed using the Statistical Package for Social Sciences (SPSS 2001 version 10.1.4). Significance was accepted at 0.05 level of probability. Resting energy expenditure in patients with advanced NSCLC, metastatic melanoma and metastatic breast cancer were compared to healthy controls using the independent $t$-test.

Changes in outcome variable between baseline and the end of chemotherapy were determined in each of the groups from paired $t$-test (weight, body fat, $\%$ fat MAMC TBK, FACT-G, energy intake, REE) and Wilcoxon sum of ranks test (CRP). $P$-values reported have been corrected for the Bonferroni adjustment to allow for the multiple testing. Values for individual skinfold measurements are presented for completeness, but no statistical analyses were undertaken on these data.

In view of the range of weight changes within each of the three groups, post hoc correlation analyses were undertaken to examine the relationships between mean energy intake, mean REE and mean CRP (average of value prior to starting chemotherapy, prior to second chemotherapy and one month after the final chemotherapy treatment) and changes in weight and body composition (body fat, FFM and MAMC) within each of the three groups, using Pearson (energy intake, REE) and Spearman (CRP) correlation coefficients.

\section{RESULTS}

\section{Patients}

In all, 43 of the 105 patients with NSCLC, 20 of the 40 patients with metastatic melanoma and 19 of the 30 patients with metastatic breast cancer were recruited. There was a large dropout from the study. The reasons for not wishing to enter and for dropout from the study are shown in Figure 1. Results are presented for the 19 NSCLC, 12 melanoma and 10 breast cancer patients who were reassessed at the end of chemotherapy. All of the patients with NSCLC, four with breast cancer and 11 with melanoma were newly diagnosed with advanced disease. The remaining patients had metastatic disease, which had progressed after previous cancer therapy for advanced disease.

Baseline characteristics of patients recruited to the study and assessed throughout chemotherapy within the advanced NSCLC, melanoma and breast cancer groups are reported in Table 1. Within the NSCLC and melanoma groups, patients assessed throughout chemotherapy were less likely to have an acute-phase protein response (APPR) at recruitment and more likely to have a favourable response to chemotherapy compared to the patients recruited the study. Non-small-cell lung cancer patients assessed throughout chemotherapy also had higher baseline performance scores than the group recruited to the study. In contrast, breast cancer patients assessed throughout chemotherapy were no more likely to have an APPR than the breast cancer patients recruited to the study, but if anything appeared less likely to have a favourable response to chemotherapy.

Among patients assessed throughout chemotherapy, those with NSCLC had experienced a significant weight loss in the 4 months prior to commencing chemotherapy. Median (range) weight change $=-7(-18-7) \%$. Weight changes in the previous 4 months among patients with melanoma and breast cancer patients were not significantly different from zero; however, some of the patients within each group had lost or gained weight (Table 1). Chemotherapy cycles lasted for between 3 and 7 months: median (range) length of chemotherapy for patients with NSCLC $=5(3-7)$ months; metastatic melanoma $=3.8(3-6)$ months and metastatic breast $=4.25(4-6)$ months. A proportion of patients in each group responded to chemotherapy (objective response; seven NSCLC, one breast cancer, two melanoma, stable disease; three NSCLC, four breast cancer and four melanoma or progressive disease; nine NSCLC, five breast cancer and six melanoma). At 1 year after recruitment into the study, 13 of the 19 patients with NSCLC, eight of the 12 patients with melanoma and three of the 10 patients with breast cancer had died. 


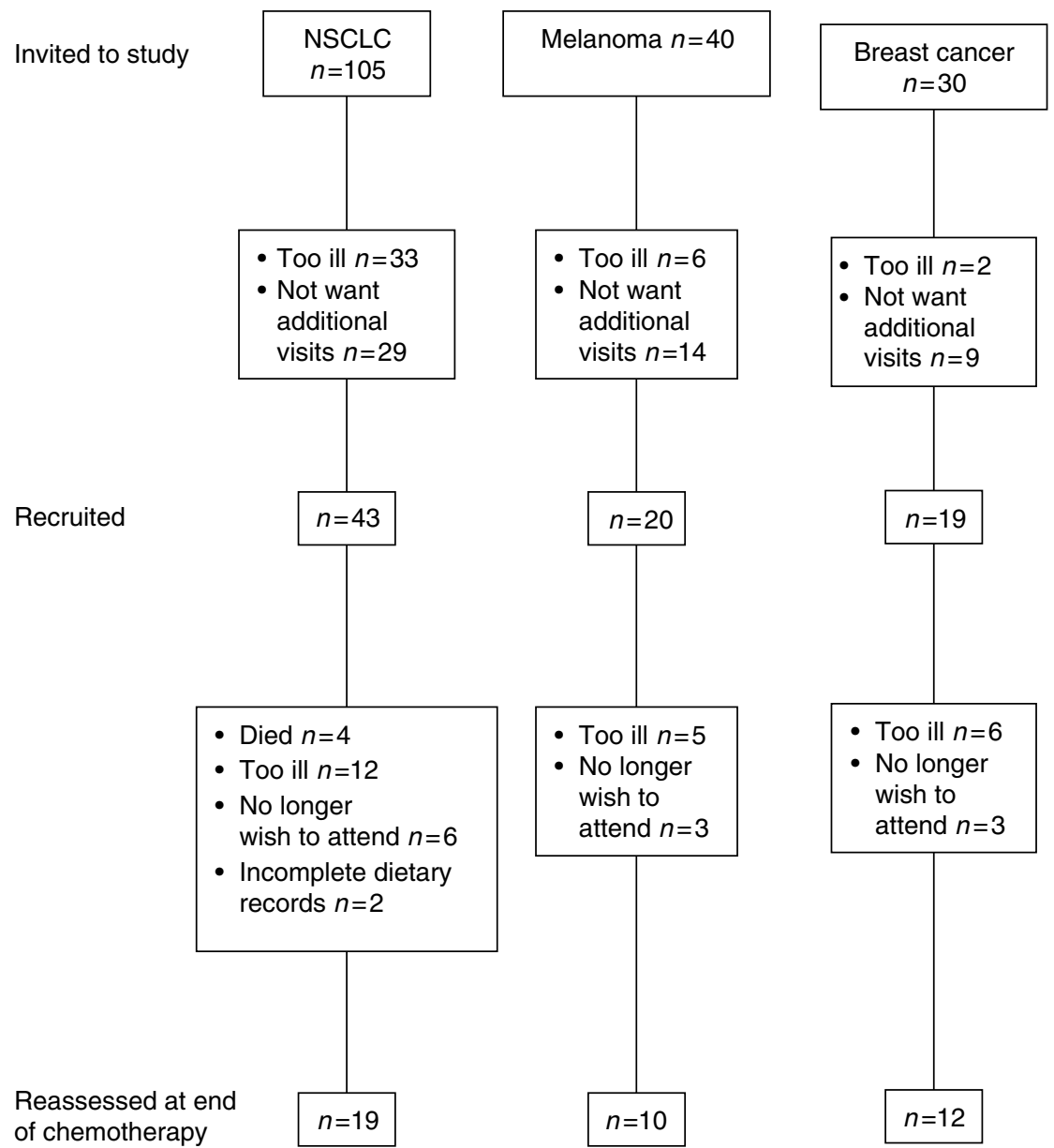

Figure I Recruitment and dropout of participants to study.

Table I Baseline characteristics of patients with advanced NSCLC, metastatic melanoma and metastatic breast cancer recruited to study and assessed $t$ hroughout chemotherapy

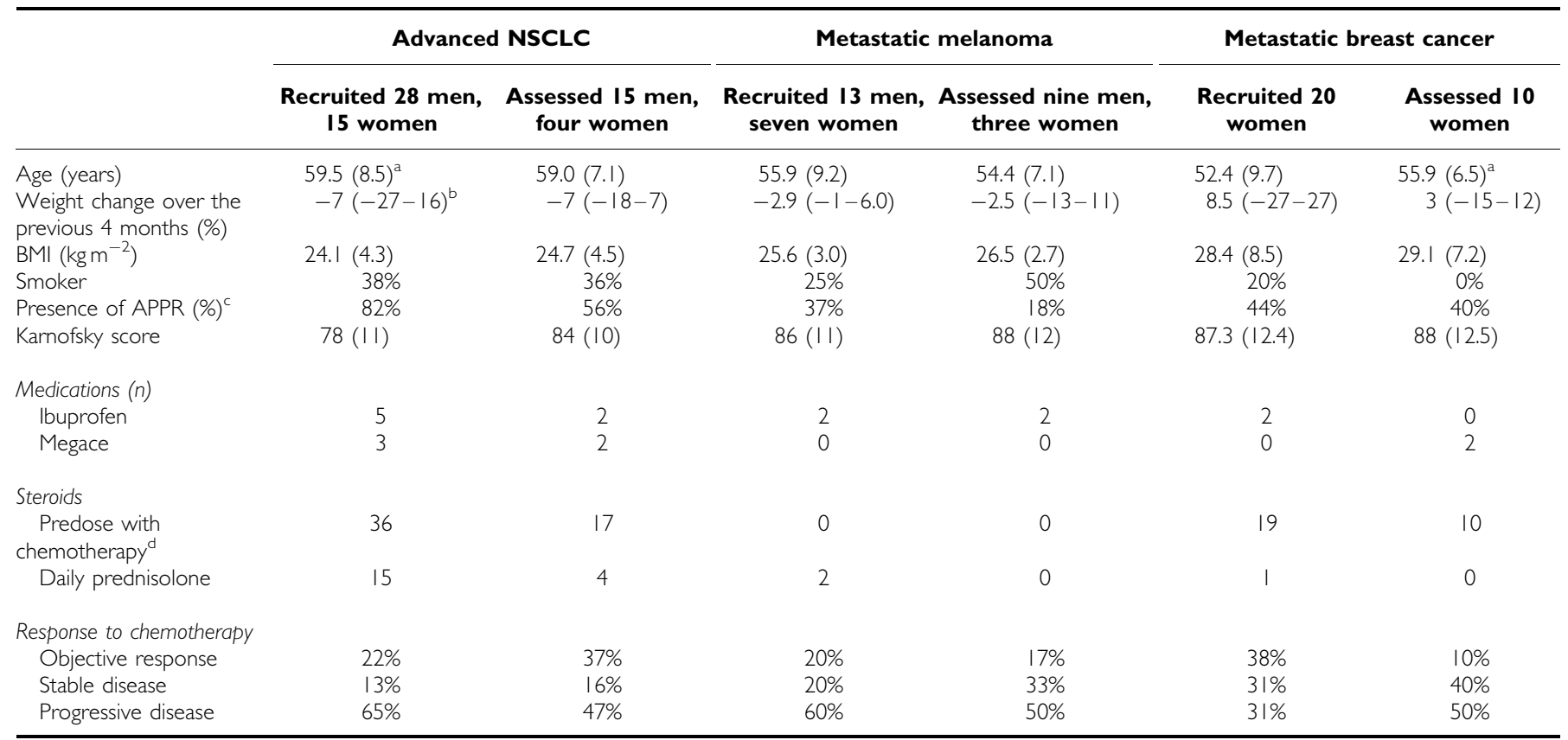

a Mean (s.d.). ${ }^{b}$ Median (range). ${ }^{~}$ The presence of an acute-phase protein response defined as CRP $>\left.10 \mathrm{mg}\right|^{-1}$ (Mahmoud et al, 2002). dPredose of dexamethasone $8-40$ mg for 3-5 days with chemotherapy. 


\section{Body mass and composition}

Body mass and composition over the course of chemotherapy are reported in Table 2a. Mean weight did not change over the course of chemotherapy; however, some of the patients within each group had appreciable gains or losses of weight. Patients with metastatic breast cancer had a significant increase in \% body fat mean change $(95 \% \mathrm{CI})=2.1(0.8-3.5) \%(P<0.05)$ and tendency to lose FFM; mean $(95 \%$ CI change $)=-1.9(-4.9-1.1) \mathrm{kg}(P=0.074)$. Mean \% body fat and FFM remained unchanged among patients with NSCLC and melanoma; however, some patients within each group had lost or gained body fat and FFM. Patients with metastatic melanoma had a significant decrease in MAMC mean $(95 \% \mathrm{CI}$ change $)=-1(-2,-0.2) \mathrm{cm}(P<0.05)$. Baseline and post chemotherapy TBK were assessed in $14 / 19$ patients with NSCLC, $10 / 12$ patients with metastatic melanoma and $8 / 10$ patients with metastatic breast cancer. Mean TBK remained unchanged in each of the groups; however, patients within each of the groups had experienced increases or decreases in TBK.

\section{Energy intake and energy expenditure}

Resting energy expenditure is expressed as absolute REE in terms of $\mathrm{kJ} / 24 \mathrm{~h}$, per $\mathrm{kg}$, per $\mathrm{kg} F \mathrm{FF}$, and in order to standardise for weight, height and age as a \% of the resting energy, expenditure was predicted from the Harris Benedict equation (\% $\mathrm{HB}$ ) (Harris and Benedict, 1919). Patients with NSCLC had a significantly higher REE compared to age- and sex-matched healthy subjects. REE for patients with NSCLC was $112(17) \%$ $\mathrm{HB}$ compared to $97.5 \% \mathrm{HB}(10.4)$ in the controls $(P<0.001)$.
The REE in patients with metastatic melanoma was 104 (11)\% HB, which was comparable to controls $101.4(9) \%$ HB $(P=0.41)$. REE in patients with metastatic breast cancer was $98.6(9.6) \% \mathrm{HB}$, which was also comparable to controls 95.0(9.5)\% $\mathrm{HB}$ $(P=0.234)$.

Changes in REE and energy intake are reported in Table $2 b$. There were no significant overall changes in REE over the course of chemotherapy, but a variable response in REE within each of the three groups. Mean REE throughout chemotherapy did not relate to change in weight, FFM or body fat over the course of chemotherapy (data not shown).

Energy intake is expressed as an absolute intake in $\mathrm{mJ}$ and $\mathrm{mJ}$ per kg body weight. Patients with melanoma and breast cancer had significant increases in intakes of both energy and protein over the course of chemotherapy $(P<0.05)$. Mean energy intake did not change for patients with NSCLC, but some patients had appreciable increases or decreases in energy intake over the course of chemotherapy. Correlations between mean energy intake throughout chemotherapy with change in weight, body fat and FFM in the three groups are shown in Table 3a. Mean energy intake throughout chemotherapy was significantly related to change in weight $(R=0.603 ; P<0.01)$ and body fat $(R=0.751 ; P<0.01)$ among patients with NSCLC (Figure $2 \mathrm{~A}$ ), and to the change in body fat among patients with breast cancer $(R=0.617 ; P<0.05$; Figure 2B). Gains in weight and body fat among patients with NSCLC and metastatic breast cancer are therefore related to higher energy intakes. Change in weight and body fat were not related to energy intake among patients with metastatic melanoma. Change in FFM and MAMC did not relate to energy intake in any of the groups.

Table 2 (a) Change in body mass and composition and health-related quality of life and (b) resting energy expenditure dietary intake and C-reactive protein over the course of chemotherapy in patients with advanced NSCLC, metastatic breast cancer and metastatic melanoma

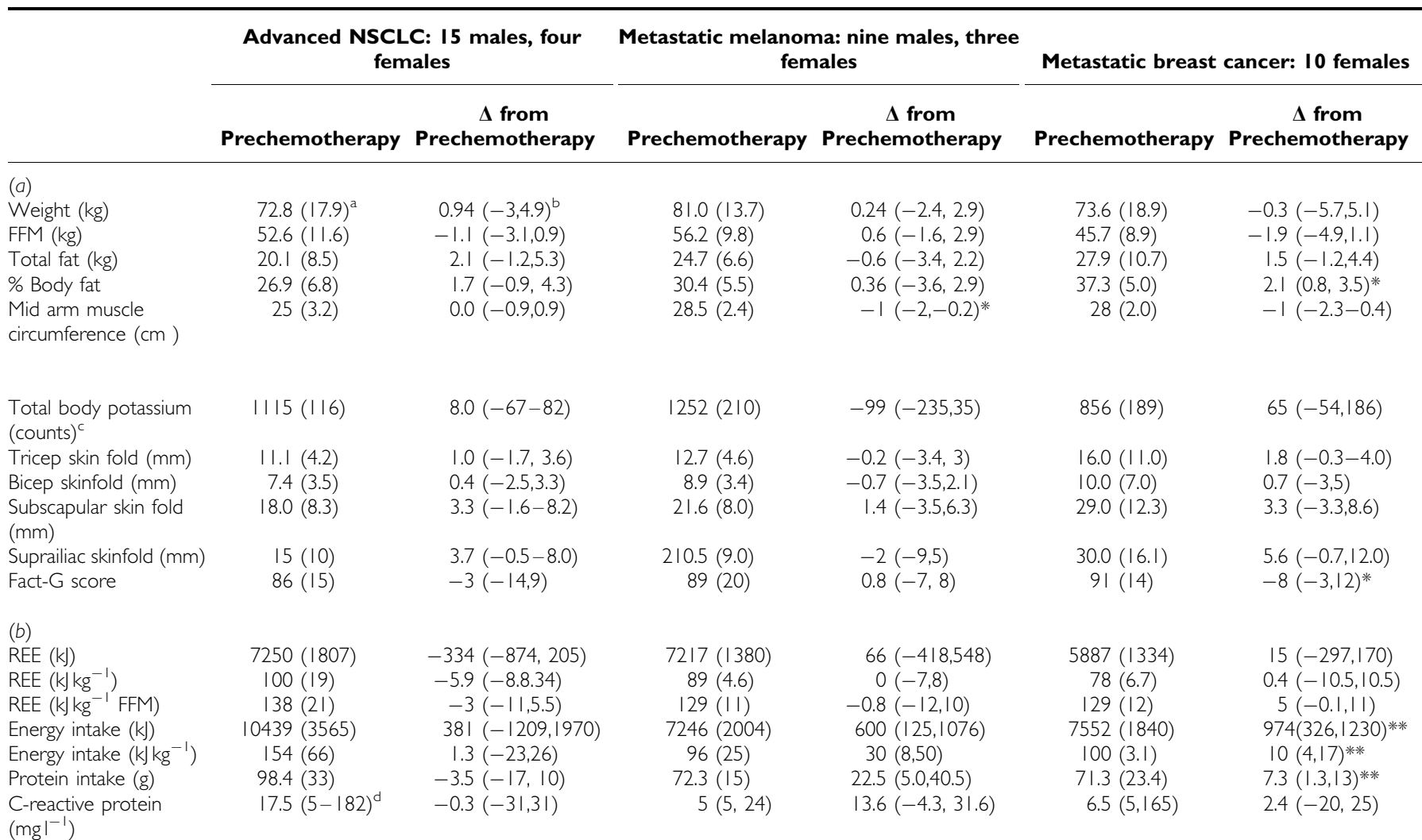

${ }^{a}$ Mean (s.d.) b Mean (95\% confidence intervals). ${ }^{\complement} \mathrm{NSCLC} n=14$; metastatic melanoma $n=10$; metastatic breast cancer $n=8$. ${ }^{\mathrm{d}}$ Median (range). FFM $=$ fat-free mass; REE $=$ resting energy expenditure. *Significant difference between prechemotherapy and post chemotherapy $(P<0.05)$. **Significant difference between prechemotherapy and post chemotherapy $(P<0.01)$ 
Table 3 (a) Pearson correlations between mean energy intake and (b) Spearman correlation between mean level of C-reactive protein over the course of chemotherapy and change in weight, fat, fat-free mass and midarm muscle circumference over the course of chemotherapy in advanced cancer patients

\begin{tabular}{|c|c|c|c|c|}
\hline & $\begin{array}{l}\text { Change } \\
\text { in weight }\end{array}$ & $\begin{array}{l}\text { Change } \\
\text { in } \\
\text { total } \\
\text { body } \\
\text { fat }\end{array}$ & $\begin{array}{l}\text { Change } \\
\text { in } \\
\text { fat-free } \\
\text { mass }\end{array}$ & $\begin{array}{c}\text { Change } \\
\text { in } \\
\text { mid-arm } \\
\text { muscle } \\
\text { circumference }\end{array}$ \\
\hline \multicolumn{5}{|l|}{ (a) } \\
\hline NSCLC $n=19$ & $0.603 *$ & $0.751 * * *$ & -0.213 & -0.196 \\
\hline Metastatic melanoma $n=12$ & 0.427 & -0.112 & 0.329 & 0.259 \\
\hline Metastatic breast cancer $n=10$ & 0.533 & $0.617^{*}$ & 0.383 & -0.050 \\
\hline \multicolumn{5}{|l|}{ (b) } \\
\hline $\operatorname{NSCLC} n=19$ & $-0.549 *$ & $-0.543 *$ & -0.069 & $-0.577 *$ \\
\hline Metastatic melanoma $n=12$ & 0.098 & -0.328 & -0.160 & $-0.617 *$ \\
\hline Metastatic breast cancer $n=10$ & -0.018 & 0.162 & 0.108 & 0.117 \\
\hline
\end{tabular}

*Correlation is significant at the 0.05 level (two-tailed). ** Correlation is significant at the 0.0 I level (two-tailed).

\section{Health-related quality of life}

Changes in FACT-G score are shown in Table 2a. Patients with metastatic breast cancer had a significant decrease in FACT-G score over the course of chemotherapy mean change $(95 \% \mathrm{CI})=8$ $(-3,-12)(P<0.05)$. Mean FACT-G score remained unchanged among patients with NSCLC and metastatic melanoma.

\section{Inflammatory response}

In all, 35 of the 43 patients recruited with NSCLC (82\%), 15 of the 40 patients with melanoma $(37 \%)$ and 13 of the $30(44 \%)$ with breast cancer had an APPR defined as a CRP $\geqslant 10 \mathrm{mgl}^{-1}$ (Mahmoud and Rivera, 2002). Among patients assessed throughout chemotherapy, 11 of the 19 (56\%) patients with NSCLC, two of the 12 with melanoma (18\%) and four of the $10(40 \%)$ with breast cancer had an APPR. There was no overall change in CRP over the course of chemotherapy in any of the groups. A higher proportion of the patients with melanoma had an APPR at the end of chemotherapy compared to baseline (4/12 compared to 2/12), while less metastatic breast cancer had an APPR at the end of chemotherapy compared to baseline (2/10 compared to 4/10). The proportion of patients with NSCLC with an APPR did not change between baseline and the end of chemotherapy (7/19 compared to $8 / 19)$.

Correlations between mean CRP over the course of chemotherapy and change in weight, body fat and FFM and MAMC are shown in Table 3b. Among patients with NSCLC, there were negative correlations between mean CRP and change in weight $\left(R_{\mathrm{s}}-0.549\right.$; $P<0.05)$, body fat $\left(R_{\mathrm{s}}-0.543 ; P<0.05\right)$ and MAMC $\left(R_{\mathrm{s}}-0.577\right.$; $P<0.05)$, but no relationship with change in FFM $(P=0.799)$. Mean CRP level did not relate to changes in weight or body fat or FFM in patients with breast cancer or melanoma. Among patients with metastatic melanoma, there was a negative correlation between mean CRP and change in MAMC $\left(R_{\mathrm{s}}-0.617 ; P<0.05\right)$. The inflammatory response was therefore linked to loss of weight body fat and MAMC among patients with NSCLC and loss of MAMC among patients with melanoma.

\section{DISCUSSION}

This study provides one of the few longitudinal assessments of energy balance (body composition, REE, dietary intake) and the systemic inflammatory response (APPR) among advanced cancer
A

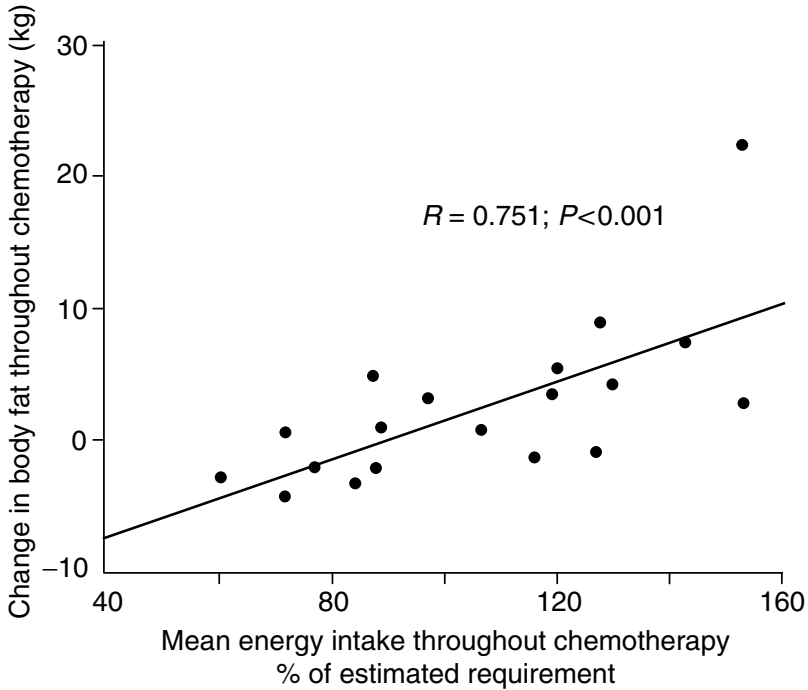

B

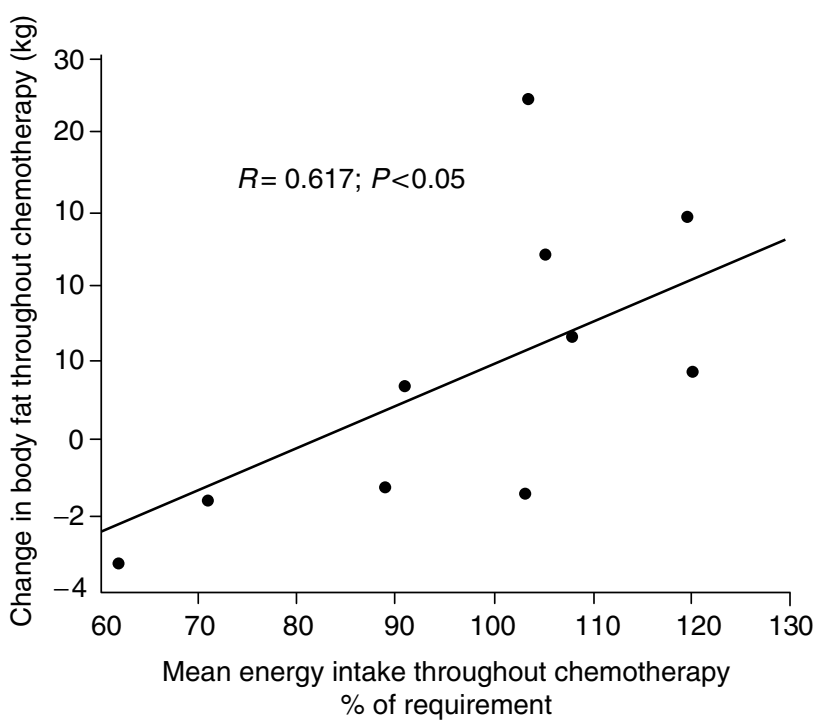

Figure 2 (A) Correlation between mean energy intake and change in body fat throughout chemotherapy among patients with NSCLC. (B) Correlation between mean energy intake and change in body fat throughout chemotherapy among patients with metastatic breast cancer.

patients receiving chemotherapy. However, the high dropout rate from the study illustrates the problem of making serial measurements in such seriously ill populations. Selection bias is introduced among the patients with NSCLC and melanoma because patients in whom a second measurement could be made were probably among the less seriously ill, but not apparently among those with metastatic breast cancer.

We did not show the anticipated fall in body weight over the course of chemotherapy among patients with NSCLC or melanoma, but there was a range of nutritional responses to chemotherapy within these groups. Patients with breast cancer did not change the overall weight, but had a propensity to gain fat and to lose FFM. The ability to meet or exceed energy requirements led to gains in weight and body fat among patients with NSCLC and metastatic breast cancer, but did not prevent loss of FFM in either group. The acute-phase response was linked to loss of weight and body fat among patients with NSCLC and loss of MAMC among patients with NSCLC and metastatic melanoma. 
Studies of wasting and cancer have mainly been conducted among patients with gastrointestinal (GI) malignancies (Bosaeus et al, 2001). We deliberately studied cancers that do not directly involve the GI tract to allow the effects of chemotherapy and the metabolic effect of the cancer being treated to be assessed. We have reconfirmed the variable change in weight among patients with NSCLC (Sarna et al, 1994). Weight loss has previously been reported among patients with metastatic melanoma (Smit et al, 1983). Weight maintenance in our patients may reflect less toxic chemotherapy regimens, and control of emesis. Loss of mid arm muscle alongside maintenance of FFM is these patients is consistent with previous reports of disproportionate loss of midarm muscle among cancer patients (Garrow, 1974). Advanced breast cancer patients are considered to maintain good nutritional status despite the presence of widespread metastatic disease (Bozzetti et al, 1981; Jardine et al, 1984), although not all studies concur (DeWys et al, 1981; Rowland-Payne et al, 1982). Gains in fat and loss of FFM among patients with breast cancer in this study represent a deterioration of nutritional status during chemotherapy.

We have confirmed the presence of an elevated REE among patients with NSCLC (Staal-van den Brekel et al, 1997a). Patients with both metastatic melanoma and metastatic breast cancer patients appeared to have a normal metabolic rate. There was a variable response in REE over the course of chemotherapy within each of the three groups. Previous reports have linked declines in REE with a response to chemotherapy (Jebb et al, 1994), the reasons for the varied response among patients in the current study are unclear.

Contrary to expectations, energy intake increased over the course of chemotherapy in patients with melanoma and breast cancer. This may in part reflect an effect of the pre-dose chemotherapy steroids among the breast cancer patients. Whether steroids would continue to influence dietary intake 3 weeks post treatment is not known. Increases in dietary intake were particularly surprising in the patients with metastatic melanoma since the majority of this population received highly emetogenic decarbazine chemotherapy and did not receive steroids. Chemotherapy-associated increases in dietary intake have previously been reported in patients with early but not metastatic breast cancer (Heasman et al, 1985). These increases are thought to be mediated by chemotherapy-associated hunger, an increased sense of well-being, or increased snacking to offset nausea (Grindel et al, 1989).

We have confirmed the prevalence of an APPR among patients with NSCLC at $82 \%$ (Scott et al, 2003). The APPR also occurred, but to a lesser extent, among patients with metastatic melanoma (37\%) and metastatic breast cancer (44\%). Patients taking antiinflammatory medications, that is, steroids or ibuprofen, were included from the analysis as they still had an APPR. C-reactive protein would, if anything, be expected to be higher in these patients if they had not taken anti-inflammatory medications. Loss of weight and body fat was related to the level of CRP among patients with NSCLC, which confirms the findings from an earlier cross-sectional study (Scott et al, 1996).

The ability to meet or exceed energy requirements led to gains in body fat but not FFM in patients with breast cancer and NSCLC. This is consistent with findings from earlier nutritional intervention studies (Evans et al, 1987; Ovesen et al, 1993). Gains in fat have not been shown to confer advantages in terms of survival, chemotherapy-associated toxicity or quality of life among patients with NSCLC (Evans et al, 1987). The declines in health-related quality of life alongside gains in body fat among patients with metastatic breast cancer in the present study suggest that gains in fat were not beneficial in this group. Gains in body fat may be particularly deleterious for women with breast cancer. Higher weight and stores of body fat are linked to poorer survival and prognosis among patients with breast cancer (Petrelli et al, 2002;
Borugian et al, 2003), most likely mediated by the associated higher levels of oestrogen (Leenen et al, 1994), insulin (Weinstock et al, 1998) and bioavailable insulin-like growth factor-1 (IGF-1) (Nam et al, 1997). Energy intake did not relate to changes in body fat among patients with metastatic melanoma in the present study. It is possible that the energy intake assessed 3 weeks after chemotherapy may not have reflected any acute decrease in energy intake in the immediate post-chemotherapy period. It also raises the possibility that changes in fat mass among patients with metastatic melanoma may be independent of energy balance and instead influenced by the presence of lipid-mobilising factors such as zinc- $\alpha 2$ glycoprotein (Russell and Tisdale, 2002; Bing et al, 2004).

Preservation of FFM remains a major therapeutic challenge in the management of the cancer patients linked to improvements in functional capacity, prognosis (Tisdale, 2001), and quality of life (Fearon et al, 2003). Our study highlights that adequate dietary intake will not lead to gains in FFM during chemotherapy. Previous studies have linked loss of FFM (Simons et al, 1999; Fearon et al, 2003) to the presence of an inflammatory response in advanced cancer patients not receiving active treatment. We were unable to establish any links between CRP level and change in FFM in any of our advanced cancer groups over the course of chemotherapy. Loss of mid-arm muscle was linked to CRP among patients with NSCLC and metastatic melanoma, suggesting that loss of peripheral muscle mass at this site was linked to the inflammatory response. Total body potassium is considered by some to be a robust method of assessing lean body mass among cancer patients (Mcmillan et al, 2000). We, however, failed to replicate a previous report that declines in TBK in cancer patients are linked to the APPR (Mcmillan et al, 1998) (data not shown). A major distinction between the present and earlier reports that linked loss of FFM and TBK to the APPR is that our cancer patients were assessed throughout chemotherapy. Loss of FFM and TBK in patients receiving chemotherapy may be a function of the chemotherapy itself, which may limit protein synthesis (Herrmann et al, 1981; Tayek and Chlebowski, 1992), or may relate to the associated lower levels of hormones such as testosterone (Aaesebo et al, 1991) and IGF-1 (Kajdaniuk and Marek, 2000). The use of predose steroids among patients with NSCLC and breast cancer is unlikely to have led to loss of FFM in the doses used (Picado et al, 1990). Declines in activity (secondary to chemotherapy associated fatigue) may be a specifically linked to loss of FFM among advanced cancer patients receiving chemotherapy. We did not assess physical activity, but preliminary studies among advanced cancer patients receiving chemotherapy have demonstrated homebased resistance and moderate exercise programmes to be efficacious in the preservation of FFM (Coleman et al, 2003).

The possible limitation of assessment of FFM from skinfolds needs to be considered. No method of assessing lean (metabolically active tissue) is entirely satisfactory, particularly among cancer patients. All techniques (body potassium, dual emission X-ray absorptiometry, body water, body density, body impedance, in vitro neutron activation analysis (IVNAA)) make assumptions about the relationship between the various body compartments and what is being measured (Burkinshaw, 1990). FFM calculated from skinfold relies on a relationship with body density (Durnin and Womersley, 1974). It is, however, the most widely used and the most robust of the techniques available. Hill et al (1978) demonstrated a very close relationship between FFM and total body nitrogen (protein) measured using IVNAA. Mid upper arm muscle circumference is often used as an index of lean or fat-free body mass, but in wasting conditions tends to diminish faster than total body FFM (Garrow, 1974). Total body potassium is considered to be an index of the functional body cell mass and muscle mass (Moore, 1980). Previous studies have shown declines of TBK in patients receiving chemotherapy with a variety of tumours (Cohn et al, 1982) and testicular cancer (Hyltander et al, 
1991). The reason for the lack of decline in TBK over the course of chemotherapy in patients in this study is unclear.

Small numbers of patients means that we were unable to assess whether response to chemotherapy influenced food intake, REE, body composition or APPR in each of the cancer groups. Response to chemotherapy has been linked to declines in REE, and preservation of FFM among patients with SCLC (Jebb et al, 1994) and declines in APPR (Staal-van den Brekel et al, 1997b). Some of the differences in body composition between the cancer groups may be in part due to gender effects (Harvie et al, 2003), but we are unable to determine these gender effects from our analysis.

This study adds to the body of data that shows the varied nutritional response to chemotherapy even within individuals with the same tumour stage. Higher energy intakes lead to gains in fat among patients with advanced breast and lung cancer. Loss of FFM throughout chemotherapy, however, does not appear to be linked to inadequate intakes of energy or protein. Declines in MAMC were linked to the presence of an APPR. Preservation of FFM alongside chemotherapy treatments may not therefore be amenable to standard nutritional repletion. Further studies should investigate the potential benefits of anti-inflammatory medications (Fearon et al, 2003) and exercise (Coleman et al, 2003) on preservation of FFM among advanced cancer patients receiving chemotherapy.

\section{ACKNOWLEDGEMENTS}

This work was supported by a grant from the Scientific Hospital Supplies, Liverpool, UK. We thank the men and women who participated in this research, and the following individuals for their invaluable help: Dr Mark Middleton, Sue Dyde, Lynn Lomax, Jackie Hodgett, Audrey Griffiths, Sharon Wade, Helen Barlow, Carol Farrell, Maria Parker, Kath Maycock, Jane Green, Marie Keegan, Brian Murby, Mike Boulton, Paul Schofield, Angela Bryan, Helen Sumner, Julie Morris, Alison Wynn-Davis and Jean Miller.

\section{REFERENCES}

Aaesebo U, Bremnes RM, Aakvaag A, Slordal L (1991) Gonadal endocrine dysfunction in patients with lung cancer: relation to responsiveness to chemotherapy, respiratory function and performance status. J Steroid Biochem Mol Biol 39: 375-380

Bing C, Bao Y, Jenkins J, Sanders P, Manieri M, Cinti S, Tisdale MJ, Trayhurn P (2004) Zinc-alpha2-glycoprotein, a lipid-mobilizing factor, is expressed in adipocytes and is up regulated in mice with cancer cachexia. Proc Natl Acad Sci USA 101: 2500-2505

Boddy K, King PC, Tothill P, Strong JA (1971) Measurement of total body potassium with a shadow shield whole-body counter: calibration and errors. Phys Med Biol 16: 275-282

Borugian MJ, Sheps SB, Kim-Sing C, Olivotto IA, Van Patten C, Dunn BP, Coldman AJ, Potter JD, Gallagher RP, Hislop TG (2003) Waist-to-hip ratio and breast cancer mortality. Am J Epidemiol 158: 963-968

Bosaeus I, Daneryd P, Svanberg E, Lundholm K (2001) Dietary intake and resting energy expenditure in relation to weight loss in unselected cancer patient. Int J Cancer 93: 380-383

Bozzetti F, Migliavacca S, Scotti A, Bonalumi MG, Scarpa D, Battici F, Ammatuna M, Pupa A, Terno G, Sequeira C, Masserini C, Emanuelli H (1981) Impact of cancer, type, site, stage and treatment on the nutritional status of patients. Ann Surg 96: 170-179

Buccheri G, Ferrigno D (2001) Importance of weight loss definition in the prognostic evaluation of non-small-cell lung cancer. Lung Cancer 34: $433-440$

Burkinshaw L (1990) Some aspects of body composition in cancer. Infusions Ther 17(Suppl 3): 57-58

Cella DF, Tulsky DS, Gray G, Sarafian B, Linn E, Bonomi A, Silberman M, Yellen SB, Winicour P, Brannon J (1993) The Functional Assessment of Cancer Therapy scale: development and validation of the general measure. J Clin Oncol 11: 570-579

Cohn SH, Vartsky D, Vaswani AN, Sawitsky A, Rai K, Gartenhaus W, Yasumura S, Ellis KJ. (1982) Changes in body composition of cancer patients following combined nutritional support. Nutr Cancer 4: $107-119$

Coleman EA, Coon S, Hall-Barrow J, Richards K, Gaylor D, Stewart B (2003) Feasibility of exercise during treatment for multiple myeloma. Cancer Nurs 26: $410-449$

DeWys WD, Begg C, Band P, Tormey D (1981) The impact of malnutrition on treatment results in breast cancer. Cancer Treat Rep 65(Suppl 5): $87-91$

Durnin JV, Womersley J (1974) Body fat assessed from total body density and its estimation from skinfold thickness: measurements on 481 men and women aged from 16-72 years. Br J Nutr 32: 77-97

Evans WK, Nixon DW, Daly JM, Ellenberg SS, Gardner L, Wolfe E, Shepherd FA, Feld R, Gralla R, Fine S (1987) A randomised study of oral nutritional support versus ad lib nutritional intake during chemotherapy for advanced colorectal and non-small cell lung cancer. J Clin Oncol 5: $113-124$
Fearon KC, Von Meyenfeldt MF, Moses AG, Van Geenen R, Roy A, Gouma DJ, Giacosa A, Van Gossum A, Bauer J, Barber MD, Aaronson NK, Voss AC, Tisdale MJ (2003) Effect of a protein and energy dense $\mathrm{N}-3$ fatty acid enriched oral supplement on loss of weight and lean tissue in cancer cachexia: a randomised double blind trial. Gut 52: $1479-1486$

Garrow JS (1974) Energy stores: their composition measurement and control. In Energy Balance and Obesity in Man pp 177-224. Amsterdam: North-Holland

Grindel CG, Cahill CA, Walker M (1989) Food intake of women with breast cancer during their first 6 months of chemotherapy. Oncol Nurs Forum 16: $401-407$

Gurney JM, Jelliffe DB (1973) Arm anthropometry in nutritional assessment: nomogram for rapid calculation of muscle circumference and cross-sectional muscle and fat areas. Am J Clin Nutr 26: 912-915

Harris JA, Benedict FG (1919) In a Biometric Study of Basal Metabolism in Man. Washington, DC: Carnegie Institution of Washington

Harvie MN, Campbell IT, Baildam A, Howell A (2004) Energy balance in early breast cancer patients receiving adjuvant chemotherapy. Breast Cancer Res Treat 83: 201-210

Harvie MN, Campbell IT, Thatcher N, Baildam A (2003) Changes in body composition in men and women with advanced non small cell lung cancer (NSCLC) undergoing chemotherapy. J Hum Nutr Diet 16: $323-326$

Heasman KZ, Sutherland RN, Campbell JA, Elhakim T, Boyd NF (1985) Weight gain during adjuvant chemotherapy for breast cancer. Breast Cancer Res Treat 5: 195-200

Hellsing K (1973) The effects of different polymers for enhancement of the antigen- antibody reaction as measured with nephelemetry in protides of the biological fluids. In Peeters $\mathrm{H}$ (ed) Vol 23. pp 579. Oxford: Pergamon Press

Herrmann VM, Garnick MB, Moore FD, Wilmore DW (1981) Effect of cytotoxic agents on protein kinetics in patients with metastatic cancer. Surgery 90: $381-387$

Hill GL, Bradley JA, Collins JP, McCarthy I, Oxby CB, Burkinshaw L (1978) Fat free body mass from skinfold thickness: a close relationship with total body nitrogen. Br J Nutr 39: 403-405

Holland B, Welch AA, Unwin ID, Buss DH, Paul AA, Southgate DAT (1991) The 5th edition of McCance \& Widdowsons. The Composition of Foods. London: HMSO

Hyltander A, Drott C, Unsgaard B, Tolli J, Korner U, Artfvidsson B, Lundholm K (1991) The effects on body composition and exercise performance of home parenteral nutrition given as an adjunct to chemotherapy of testicular carcinoma. Eur J Clin Invest 21: $413-420$

Jardine LG, Levin L, Gevers W (1984) Comparison of muscle and fat wasting in patients suffering from breast and other cancers: an anthropometric study. Breast Cancer Res Treat 4: 227-232 
Jebb SA, Osborne RJ, Dixon A, Bleehen N, Elia M (1994) Measurements of resting energy expenditure and body composition before and after treatment of small-cell lung cancer. Ann Oncol 5: 915-919

Kajdaniuk D, Marek B (2000) Influence of adjuvant chemotherapy with cyclophosphamide, methotrexate and 5-fluorouracil on plasma insulinlike growth factor-I and chosen hormones in breast cancer premenopausal patients. J Clin Pharm Ther 25: 67-72

Karnofsky DA, Burchenel JH (1949) The clinical evaluation of chemotherapeutic agents in cancer. In Evaluation of Chemotherapeutic Agents McCleod CM (ed). pp 191-205. New York: Columbus University Press

Leenen R, van Der Kooy K, Seidell JC, Deurenberg P, Koppeschaar HP (1994) Visceral fat accumulation in relation to sex hormones in obese men and women undergoing weight loss therapy. J Clin Endocrinol Metab 78: $1515-1520$

Mahmoud FA, Rivera NI (2002) The role of C-reactive protein as a prognostic indicator in advanced cancer. Curr Oncol Rep 4: 250-255

McMillan DC, Scott HR, Watson WS, Preston T, Milroy R, McCardle CS (2000) Lean body mass in cancer patients with weight loss. Clin Nutr 19: $403-406$

McMillan DC, Watson WS, Preston T, McCardle CS (1998) Longtitudinal study of body cell mass depletion and the inflammatory response in cancer patients. Nutr Cancer 31: 101-105

Moore FD (1980) Energy and maintenance of the body cell mass. JPEN 4: $228-260$

Nam SY, Lee EJ, Kim KR, Cha BS, Song YD, Lim SK, Lee HC, Huh KB (1997) Effect of obesity on total and free insulin-like growth factor (IGF)1 , and their relationship to IGF-binding protein (BP)-1, IGFBP-2, IGFBP3, insulin, and growth hormone. Int J Obes Relat Metab Disord 21: 355 359

Ovesen L, Allingstrup L, Hannibal JM, Mortensen EL, Hansen OP (1993) Effect of dietary counseling on food intake, body weight, response rate, survival, and quality of life in cancer patients undergoing chemotherapy: a prospective, randomised study. J Clin Oncol 11: $2043-2049$

Petrelli JM, Calle EE, Rodriguez C, Thun MJ (2002) Body mass index, height, and postmenopausal breast cancer mortality in a prospective cohort of US women. Cancer Causes Control 13: 325-332

Picado C, Fiz JA, Montserrat JM, Grau JM, Fernandez-Sola J, Luengo MT, Casademont J, Agusti-Vidal A (1990) Respiratory and skeletal muscle function in steroid-dependent bronchial asthma. Am Rev Respir Dis 141: $14-20$

Rowland-Payne CM, Abbott M, Jones JM, Powles TJ, Coombes RC (1982) Weight loss during therapy for advanced breast cancer. Clin Oncol 8: $33-38$

Russell ST, Tisdale MJ (2002) Effect of a tumour-derived lipid-mobilising factor on glucose and lipid metabolism in vivo. Br J Cancer 87: 580-584
Sarna L, Lindsey AM, Dean H, Brecht ML, McCorkle R (1994) Weight change and lung cancer: relationships with symptom distress, functional status, and smoking. Res Nurs Health 17: $371-379$

Scott HR, McMillan DC, Brown DJ, Forrest LM, McArdle CS, Milroy R (2003) A prospective study of the impact of weight loss and the systemic inflammatory response on quality of life in patients with inoperable nonsmall cell lung cancer. Lung Cancer 40: 295-299

Scott HR, McMillan DC, Crilly A, McArdle CS, Milroy R (1996) The relationship between weight loss and interleukin 6 in non-small-cell lung cancer. Br J Cancer 73: $1560-1562$

Simons JP, Schols AM, Buurman WA, Wouters EF (1999) Weight loss and low body cell mass in males with lung cancer: relationship with systemic inflammation, acute-phase response, resting energy expenditure, and catabolic and anabolic hormones. Clin Sci (Lond) 97: 215-223

Smit JM, Mulder NH, Sleijfer DT, Bouman JG, Veeger W, Schraffordt Koops $\mathrm{H}$ (1983) The effect of continuous enteral tube feeding on various nutritional parameters in patients with disseminated malignant melanoma during intensive chemotherapy. Clin Nutr 1: 335-341

Staal-van den Brekel AJ, Schols AMWJ, Dentener MA, ten Velde GPM, Buurman WA, Wouters EFM. (1997b) The effects of treatment with chemotherapy on energy metabolism and inflammatory mediators in small cell lung cancer. Br J Cancer 76: 1630-1635

Staal-van den Brekel AJ, Dentener MA, Schols AM, Buurman WA, Wouters EF. (1995) Increased resting energy expenditure and weight loss are related to a systemic inflammatory response in lung cancer patients. $J$ Clin Oncol 13: 2600-2605

Staal-van den Brekel AJ, Schols AM, Dentener MA, ten Velde GPM, Buurman WA, Wouters EF (1997a) Metabolism in patients with smallcell lung carcinoma compared with patients with non-small cell lung carcinoma and healthy controls. Thorax 52: $338-341$

Tayek JA, Chlebowski RT (1992) Metabolic response to chemotherapy. J Parenteral Enteral Nutr 16(6 Suppl): 65S-71S

Tisdale MJ (2001) Loss of skeletal muscle in cancer: biochemical mechanisms. Front Biosci 6: D164-D174

UICC (1987) Anonymous evaluation of the cancer patient and the response to treatment. In: UICC Manual of Adult and Paediatric Medical Oncology Monfardini S, Brunner K, Crowther D (eds) pp 22-38. Berlin: Springer

Weinstock RS, Dai H, Wadden TA (1998) Diet and exercise in the treatment of obesity: effects of 3 interventions on insulin resistance. Arch Intern Med 158: $2477-2483$

Wigmore SJ, Plester CE, Ross JA, Fearon KCH (1997) Contribution of anorexia and hypermetabolism to weight loss in anorectic patients with pancreatic cancer. Br J Surg 84: 196-197

World health Organisation (1979) Handbook for Reporting Results for Cancer Treatment. WHO Offset Publication Vol 48. Geneva: WHO 